\title{
ARQUEOTURISMO NO CERRADO E NA AMAZÔNIA: DOIS PEDAÇOS DE UM MESMO POTE
}

Renata de Godoy ${ }^{1}$

\section{RESUMO}

Este artigo compara o Turismo Arqueológico, ou Arqueoturismo, em duas situações distintas no Brasil: um conjunto de sítios paleolíticos no Distrito Federal e um sítio colonial, onde o turismo tem sido explorado na Amazônia Brasileira, no Pará. Em Brasília, fruto de uma pesquisa de doutorado, o turismo foi analisado como uma opção de uso e de gestão do patrimônio com baixíssima visibilidade e consequente baixo potencial turístico. E na Amazônia, fruto de uma pesquisa em andamento de pós-doutoramento, o turismo tem sido avaliado enquanto ferramenta de preservação e de inclusão do público. Nas duas pesquisas, constata-se uma grande expectativa dos públicos em relação ao aproveitamento turístico, e o baixo aproveitamento da atividade nos sítios analisados até o momento. Nos dois estudos, notam-se benefícios de natureza coletiva, elencados como capitais simbólicos.

Palavras-chave: Turismo Arqueológico, Brasília, Oficina Lítica, Amazônia, Marajó

\begin{abstract}
This article analysis Archaeological Tourism, or Archaeotourism, in two distinct case studies in Brazil: a set of Paleolithic archaeological sites in the Federal District and a colonial site in the Amazon region, located in the state of Pará. In Brasília, where a $\mathrm{PhD}$ research took place, the analysis considered tourism as a very low visibility option for usage and management for the cultural heritage, consequently with low tourism potential. In the Amazon, where a post-doctoral research has been conducted, tourism is challenged as a tool for public inclusion and heritage preservation. In both l've learned that great expectation of many stakeholders regarding impending tourism usage is standard, as is the low level of tourism activity applied on the sites studied so far. In both benefits for stakeholders appeared as symbolic capital.
\end{abstract}

Keywords: Archaeological Tourism, Brasília, Quarry-based Lithic Site, the Amazon, Marajó

\section{RESUMEN}

Este artículo compara el Turismo Arqueologico, el Arqueoturismo, en dos situaciones diferentes en Brasil: un conjunto de sitios paleoliticos en Distrito Federal y un sitio colonial donde el turismo se ha explorado en la Amazonia brasileña, en Pará. En Brasilia, el fruto de una investigación de doctorado, el turismo se analiza como una opción de uso y manejo del Patrimonio con muy poca visibilidad y el consiguiente bajo potencial turistico. Y en la Amazonía, fruto de una búsqueda en curso de posdoctorado, el turismo ha sido evaluado como una herramienta de inclusión publica. En ambos estudios hay una gran expectativa del público en relación con el aprovechamiento turístico, y la baja utilización de la actividad en sitios analizados hasta el momento. En los dos estudios se observaron beneficios de carácter colectivo, catalogados como capitales simbólicos.

Palabras clave: Turismo Arqueológico, Brasília, Oficina Lítica, Amazonas, Marajó

1 Pós-doutoranda no Programa de Pós-Graduação em Antropologia, Universidade Federal do Pará (PPGA/UFPA). E-mail: godoy@ufl.edu

\begin{tabular}{|l|l|l|l|l|l|l|}
\hline (C) Rev. Arqueologia Pública & Campinas, SP & v. 9 & n. 2 & p.87-107 & DEZ 2015 & ISSN 2237-8294
\end{tabular}




\section{Introdução}

Hoje em dia, falar em Turismo Arqueológico ou Arqueoturismo deixou de ser um tabu, mas continua sendo um tema controverso. No Brasil, nos últimos anos, a quantidade de pesquisas e pesquisadores envolvidos com o tema aumentou substancialmente. Estamos falando de um país continental, cercado de vizinhos onde o patrimônio arqueológico monumental desvia todos os holofotes em termos de uso turístico. Mesmo assim, no país, o tema tem recebido atenção especialmente por meio intelectual por parte de pesquisadores brasileiros, o que envolve não apenas arqueólogos, mas também profissionais ligados ao Turismo. Apresento neste artigo dois exemplos distintos que em níveis diferentes incluem o turismo como uma alternativa de gestão: um conjunto de sítios paleolíticos localizado no Brasil Central e uma pesquisa em andamento que visa avaliar regionalmente patrimônios arqueológicos na Amazônia Brasileira (Mapa 1). São situações diferentes em todos os níveis, que se encaixam no mesmo ideal e talvez no mesmo fim: desenvolver uma atividade que visa lucro como forma de preservar o patrimônio arqueológico.

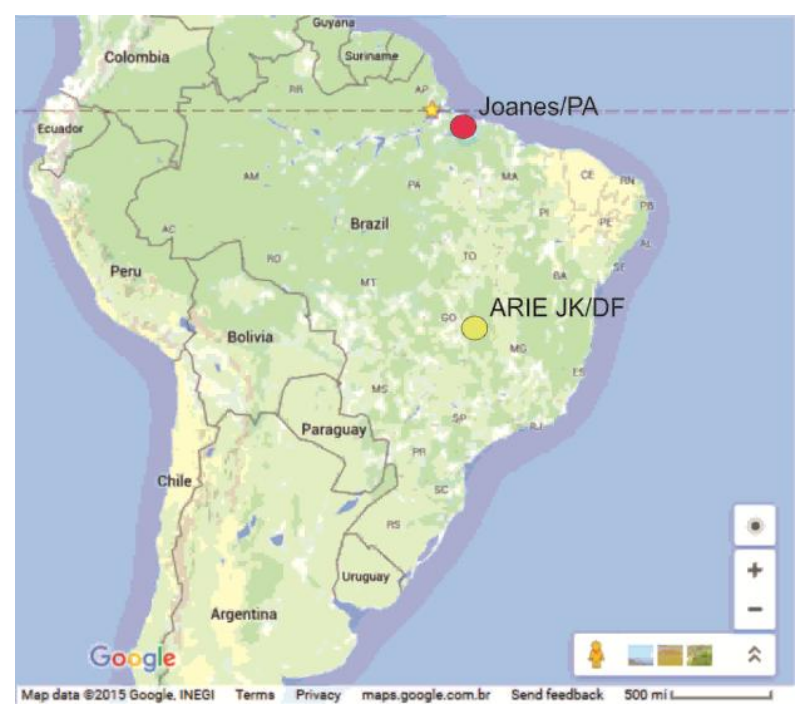

Mapa 1: localização dos dois estudos de caso. Google Maps adaptado por Godoy, 2015.

Atualmente não se pode negar que a integração entre o turismo e a arqueologia tem crescido de modo geral, e no Brasil não tem sido diferente. De fato os turistas se interessam pela arqueologia antes dos próprios pesquisadores se preocuparem com o turismo arqueológico (LOVATA, 2011). O lazer intrínseco aos monumentos arqueológicos é conhecido há tempos, e segundo Darvill (1995) mesmo aqueles menos divulgados são altamente valorizados como locais de interesse de curiosos acostumados a caminhadas e escaladas, por fotógrafos e artistas, entre outros. O turismo arqueológico já é uma prática comum no mundo todo, sobretudo em sítios considerados monumentais e assim com maior visibilidade pública, ou em acervos de coleções bem conservadas e adequadamente divulgadas. 
O Turismo é uma das indústrias mais poderosas no mundo atual. Como tal implica em sua aplicação atividades de administração, planejamento e lucro. Apesar de sua natureza destrutiva e negativa, existe um consenso de que se consciente e previamente planejado o Turismo Cultural, conceito que enquadra o tema deste artigo, pode não apenas prover financeiramente ações de preservação como também incrementar ações de divulgação e educação do bem cultural.

Hoje em dia, o Turismo Arqueológico tem sido considerado uma importante ferramenta para gestores culturais e arqueólogos que lidam com o público. Contudo, a união entre um setor que prioritariamente visa lucro com outro que busca a preservação de bens culturais nunca deixará de ser um processo complexo, e ainda é para muitos uma estratégia essencialmente contraditória. A proposta de implantação de Turismo Arqueológico costuma ser bem vista por pessoas das comunidades que anseiam pelos benefícios econômicos que podem ser gerados por tal atividade. No entanto, muitos não veem com bons olhos a inserção de visitantes no seu dia-a-dia, especialmente nas comunidades tradicionais.

Os dois exemplos apresentados a seguir são distintos também nesta faceta. Em Brasília, a pesquisa $^{2}$ não visava analisar exclusivamente o turismo (e foi aplicado em um local onde não há atividade turística formalmente desenvolvida), mas buscava a opinião de públicos aparentemente sem nenhum vínculo cultural sobre patrimônio arqueológico local. Na Amazônia ${ }^{3}$, especificamente até o momento em um distrito do Arquipélago do Marajó chamado Joanes, os atritos em relação à atividade turística esbarram na própria característica da comunidade, que convive com estranhos invadindo seus espaços enquanto turistas e enquanto empreendedores turísticos. A reação dos públicos certamente difere, mas até o momento, os efeitos do aproveitamento turístico nos sítios arqueológicos analisados em ambos os estudos de caso têm se mostrado semelhante. Tais conclusões preliminares são expostas a seguir, visando contribuir sobre a discussão do Arqueoturismo no Brasil.

Este artigo apresenta primeiramente uma discussão acerca do Turismo Arqueológico, evidenciando sua demanda atual no Brasil e no mundo, assim como a perspectiva teórica do trabalho que ressalta conceitos chave atrelados ao mesmo e seu vínculo direto à pesquisa antropológica. A seguir, apresenta os dois estudos de caso brevemente, ressaltando as metodologias aplicadas e seus resultados. As considerações finais evidenciam o contraste dos dados coletados no Distrito Federal e no Pará e apresentam semelhança nos resultados, e assim justifica a discussão proposta que indica o turismo arqueológico como gerador de capital simbólico ${ }^{4}$ em ambas as localidades.

\footnotetext{
${ }^{2}$ Pesquisa de doutorado defendida em 2012, no Departamento de Antropologia da Universidade da Flórida/EUA e financiada por bolsa de doutorado pleno no exterior/GDE do CNPq.

${ }^{3}$ Pesquisa de Pós-doutoramento em andamento desde 2013, financiada em princípio por bolsa PDJ do CNPq e atualmente por bolsa PNPD da CAPES, vinculada ao Programa de Pós-Graduação em Antropologia da Universidade Federal do Pará (PPGA/UFPA).

${ }^{4}$ Como definido por Bourdieau, em O Poder Simbólico o Capital Simbólico pode ser entendido como um recurso ou poder que equivale a sentimentos de honra e/ou prestígio entre indivíduos (BOURDIEAU, 2000).
} 


\section{Revista de Arqueologia Pública}

\section{Turismo arqueológico - um desafio a ser vencido}

O estudo do Turismo Arqueológico como ferramenta de preservação cultural e/ou de divulgação patrimonial se encaixa no ramo em crescimento na disciplina conhecido como Arqueologia Pública, que lida diretamente com as questões ligadas às responsabilidades sociais, legal e moral dos arqueólogos perante a sociedade de modo geral. Atualmente está cada vez mais difícil ignorar tais responsabilidades, intimamente relacionadas a questões éticas, econômicas, políticas e ideológicas, e na maioria das vezes submetidas e influenciadas por interesses de diversos atores e grupos sociais. Além do turismo, termos como arqueologia comunitária, repatriação de bens arqueológicos, musealização, educação patrimonial, e gestão compartilhada têm se tornado comum nos debates arqueológicos. São mecanismos de integração entre pesquisa científica e comunidades que refletem as preocupações da própria sociedade atual, que tende a se tornar cada vez mais consciente dos valores culturais e de seus direitos perante o patrimônio cultural.

Combinar os termos 'arqueologia' e 'público' é um assunto em voga ultimamente, apesar de não ser uma ideia nova. Nos anos de 1970, a dita Arqueologia Pública foi apresentada como um sinônimo de Gestão do Patrimônio Arqueológico nos Estados Unidos (MCGIMSEY, 1972), como forma de diferenciação com pesquisas de caráter eminentemente científico. Desde então, tais práticas receberam influências teóricas diversas, em especial do Marxismo, da Arqueologia Crítica e da Pós-processual, bem como foi fortemente modificada pelo fortalecimento de códigos de ética da disciplina, ampliando seu foco para as ditas minorias étnicas e visando maior acesso a direitos civis negligenciados (MERRIMAN, 2004). Como resultado hoje, entende-se que a Arqueologia Pública não é diferente nem uma adicional da prática arqueológica, e sim uma abordagem que gera outras perguntas de pesquisa e novas formas de conhecimento como consequência (HECKENBERGER, 2008: 252).

Este é um campo da disciplina especialmente preocupado com diferentes públicos e seus respectivos interesses (MERRIMAN, 2004). Para alguns autores (incluindo a autora deste artigo), a Arqueologia Pública representa uma forma de Antropologia Aplicada, como uma maneira de tornar a disciplina compreensível, democrática e socialmente relevante para todos (LUCAS, 2004; MCDAVID, 2004; SHACKEL, 2004). Significa não apenas suprir interesses sociais, mas também criar mecanismos eficazes para interagir com o público, estar aberto e apto ao diálogo com ele e com outros profissionais também. É uma maneira de fazer do patrimônio arqueológico parte integral de determinada comunidade (SHACKEL, 2004: 14). Fazer Arqueologia Pública (se é que existe outra forma de arqueologia!) é buscar engajamento com as comunidades, é entender seus vínculos com o passado e suas necessidades no presente. E pesquisar o impacto e o benefício que o uso turístico do patrimônio arqueológico pode gerar tem tudo a ver com novas formas de vínculo e novas demandas do presente em relação ao passado disponibilizado sob a forma da cultura material, seja pelas coleções seja pela paisagem.

\begin{tabular}{|l|l|l|l|l|l|l|} 
(C) Rev. Arqueologia Pública & Campinas, SP & v. 9 & n. 2 & p.87-107 & DEZ 2015 & ISSN 2237-8294
\end{tabular}




\section{Revista de Arqueologia Pública}

No Brasil, o número de publicações exclusivamente sobre turismo na arqueologia tem crescido muito desde os anos 2000, incluindo livros editados (FUNARI \& PINSKY, 2001; SCATAMACCHIA, 2005; FIGUEIREDO, S. L. et al., 2012), artigos científicos (VELOSO \& CAVALCANTI, 2007; ALFONSO, 2009; MACHADO et al., 2009; MELLO \& DANTAS, 2014), e trabalhos acadêmicos (ONUMA, 2007; MIRANDA, 2010; GUIMARÃES, 2012), além de inúmeras páginas na internet que comprovam como este assunto tem chamado a atenção dos pesquisadores e profissionais envolvidos. Na Amazônia, este panorama também se repete com contribuições recentes e específicas sobre o tema (FIGUEIREDO, 2005; PEREIRA \& FIGUEIREDO, 2005; MOREIRA, 2010; LIMA et al., 2013; CERQUEIRA \& PEREIRA, 2014). Este fato é ainda mais notório visto que os sítios arqueológicos brasileiros, em sua grande maioria, sofrem pela aparente falta de apelo turístico devido à aclamada ausência de monumentalidade, e mais ainda por ser um país que ainda não inclui sistematicamente o estudo da pré-história ou da arqueologia nos currículos escolares.

Mas apesar da atenção dada ao assunto, a parceria entre arqueologia e turismo ainda não é efetiva, e esta deficiência não é uma exclusividade do Brasil. Muitos já reconhecem e até discorrem sobre a necessidade dela, mas a comunidade arqueológica ainda não está integrada à indústria do turismo (PINTER, 2005). De fato, até bem pouco tempo atrás, perdurava a crítica de que o turismo era invisível para os antropólogos de maneira geral, apesar do óbvio e recorrente contato entre comunidades e turistas, que notoriamente causa diferentes tipos de interações sociais e que definitivamente merece ser investigada (NUŇES, 1989).

O Turismo Arqueológico, em termos conceituais, se enquadra no grande guarda-chuvas chamado Turismo Cultural. Trata-se de um segmento em crescimento dessa disciplina que visa atrair pessoas interessadas em visitar destinações culturais. Entende-se que o Turismo Arqueológico esteja diretamente atrelado ao conceito amplo do Turismo Cultural, definido por McKercer and du Cross (2002: 6) como um segmento que engloba uma ampla rede de atividades relacionadas, incluindo turismo histórico, étnico, artístico, turismo em museus entre outros. Tais atividades têm em comum recursos culturais, problemas de gerenciamento, assim como aspiram para um mesmo fim.

$\mathrm{O}$ uso de arqueologia para fins turísticos, no entanto, requer um conceito mais específico que remete ao Turismo Patrimonial. Trata-se de uma definição aparentemente objetiva, como um tipo de turismo aplicado em localidades reconhecidas como patrimônio cultural, mas esta também apresenta suas variações. Alguns autores entendem que o Turismo Cultural e o Patrimonial sejam sinônimos, visto que ambos apresentam como atrativo algo único e especial, e que assim também seja compreendido pelos moradores locais (CALDWELL, 1996), o que pode ser considerada uma definição excessivamente ampla e vaga. Definições menos abrangentes classificam o Turismo Patrimonial como um ramo do Turismo Cultural, ligado à interpretação e representação do passado (SMITH, 2003). Swarbrooke (1994) define Turismo Patrimonial como uma atividade na qual a principal motivação do consumidor e a principal atração do local seja um patrimônio cultural. Já Poria, Butler e Airey (2003) definem como uma categoria de turismo na qual a maior motivação para 
a visita seja a característica do local como ferramenta para que o turista perceba a sua própria identidade cultural. O Turismo Arqueológico, ou Arqueoturismo, nada mais é do que outro segmento do Turismo Patrimonial, no qual a principal atração é o remanescente arqueológico (MANZATO, 2005; BAWAYA, 2006).

Outro segmento turístico que está intimamente relacionado ao Turismo Arqueológico é o Ecoturismo, que se preocupa com o equilíbrio entre comunidades e seu meio ambiente. Em geral essa modalidade também tem como objetivo o baixo impacto causado ao meio no qual esteja inserido, e uma associação mais constante com o desenvolvimento sustentável (GUTIERREZ et al., 2005). Os conceitos sobre o que faz parte do Turismo Cultural podem variar, mas os princípios básicos associados a tal atividade são os mesmos daqueles ligados ao Turismo Sustentável e ao Ecoturismo, o que pode ser compreendido como o caráter principal da atividade turística que inclua o patrimônio cultural como um bem a ser consumido.

A identificação do tipo de turista que opta por destinações culturais também é controversa. Smith (2003) os classifica como educados e intelectualmente motivados, em geral abertos a experimentar novos lugares. Para Cogswell (1996), esse turista se preocupa com autenticidade e com uma experiência de alta qualidade, podendo optar por viajar grandes distâncias para atingir tais objetivos. Robinson (1999) afirma que o turista que se interessa por patrimônio cultural é basicamente caracterizado como um viajante independente, ou seja, o oposto do turista que escolhe atrativos conhecidos como Turismo de Massa.

Independente do estímulo e do tipo de turista que esteja disposto a visitar destinações culturais, o fato é que a atividade turística tem o poder de reunir pessoas de diversas etnias e com diversos olhares, interpretações e expectativas em relação ao bem cultural a ser consumido, e esses encontros carregam um grande potencial para gerar conflitos entre visitantes e moradores locais (BONIFACE \& FOWLER, 1993; BONIFACE, 1999). Profissionais do turismo sabem disso, e têm proposto métodos para minimizar tais conflitos com diversas abordagens ${ }^{5}$.

\section{O turismo nos dois exemplos - Cerrado ${ }^{6}$ versus Amazônia ${ }^{7}$}

\footnotetext{
${ }^{5}$ Turismo de Base Local que visa melhorar a qualidade de vida da comunidade anfitriã, com respeito ao meio ambiente (SEABRA, 2007: 12); "Stakeholder Theory", que em projetos desse tipo tem sido usada para auxiliar planejamento integrado e gestão compartilhada por grupos diversos (EASTERLING, 2005); "Stakeholder Collaboration", que combina gestão do patrimônio cultural e envolvimento popular durante o desenvolvimento do projeto turístico, um método considerado rentável porque minimiza conflitos em longo prazo (AAS et al., 2005); "Collaboration Theory", descrita por Jamal e Getz (1995: 187) como um processo conjunto e autônomo de tomada de decisão entre as principais lideranças da comunidade.

${ }^{6}$ Segundo o Ministério do Meio Ambiente (GOVERNO, 2015a) o bioma Cerrado é o segundo maior da América do Sul, localizado nos estados de Goiás, Tocantins, Mato Grosso, Mato Grosso do Sul, Minas Gerais, Bahia, Maranhão, Piauí, Rondônia, Paraná, São Paulo e Distrito Federal, além dos encraves no Amapá, Roraima e Amazonas. O Cerrado brasileiro é reconhecido como a savana mais rica do mundo. Além dos aspectos ambientais, ele possui grande importância social; muitas 
Comparar contextos tão distintos nos dois maiores biomas brasileiros, com dados coletados por pesquisas díspares provavelmente deixa o leitor incrédulo do resultado final. A minha experiência em Brasília durante o doutorado foi o grande motivador para elaborar uma pesquisa específica sobre Turismo Arqueológico em um contexto diferente, com a possibilidade de estudar sítios com grande potencial turístico associado a comunidades tradicionais, como ainda é possível na Amazônia. Os estudos de caso diferem também por características fundamentais de aproveitamento turístico: acessibilidade, visibilidade e potencial de musealização.

Em Brasília, os sítios paleolíticos ficam praticamente invisíveis na paisagem, além de serem localizados em área rural de difícil acesso. Trata-se de um conjunto de sítios líticos do tipo oficina localizados numa área de proteção ambiental, a ARIE Parque JK, referida ao longo do texto simplesmente como Parque. A foto 1 mostra sítio DF-PA-11 (também conhecido como Taguatinga), mas o que se pode ver é apenas a canalização de água e esgoto aérea que foi feita assim por negociação de mitigação de impacto com o empreendedor devido à inegável significância científica do local. Especificamente neste sítio foi resgatada também, associada aos raspadores planoconvexos em quartzito comuns nos outros sítios locais, uma ponta de projétil em quartzo hialino que pode recuar ainda mais a antiguidade dos vestígios arqueológicos no Parque, caracterizando-os entre os mais antigos já registrados em solo brasileiro. A foto 2 mostra um exemplo do tipo de estrutura visível em todos os sítios líticos do Parque: afloramentos de quartzito com retiradas, característico de sítios do tipo oficina lítica.

populações sobrevivem de seus recursos naturais, incluindo etnias indígenas, quilombolas, geraizeiros, ribeirinhos, babaçueiras, vazanteiros.

${ }^{7}$ Segundo o Ministério do Meio Ambiente (GOVERNO, 2015b) o bioma Amazônia é o maior do Brasil e a bacia hidrográfica Amazônica a maior do mundo. Localiza-se na chamada Amazônia Legal, que abrange todos os estados da região Norte, e parte dos estados de Mato Grosso e Maranhão (mais de $60 \%$ do território nacional). Seus recursos naturais representam uma abundante fonte de riqueza natural. A região abriga também grande riqueza cultural, incluindo o conhecimento tradicional sobre os usos e a forma de explorar esses recursos naturais sem esgotá-los nem destruir o meio ambiente. 


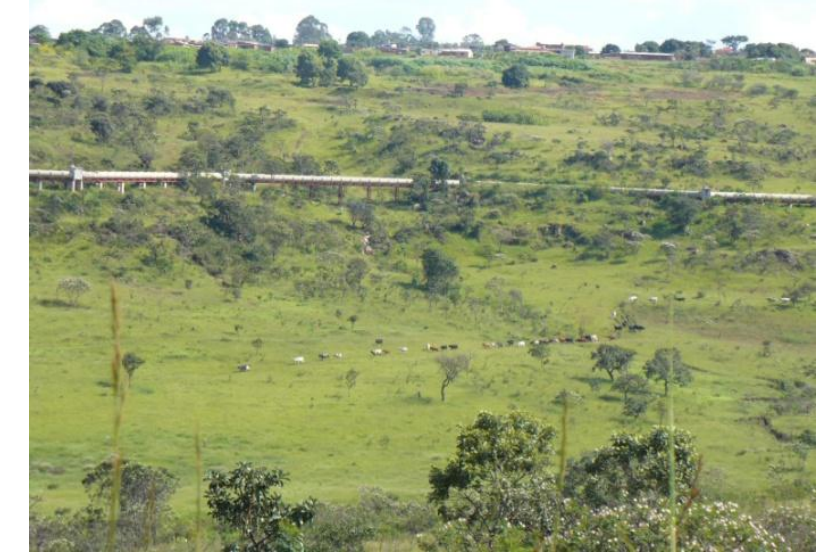

Foto 1: Sítio DF-PA-11 ou Taguatinga

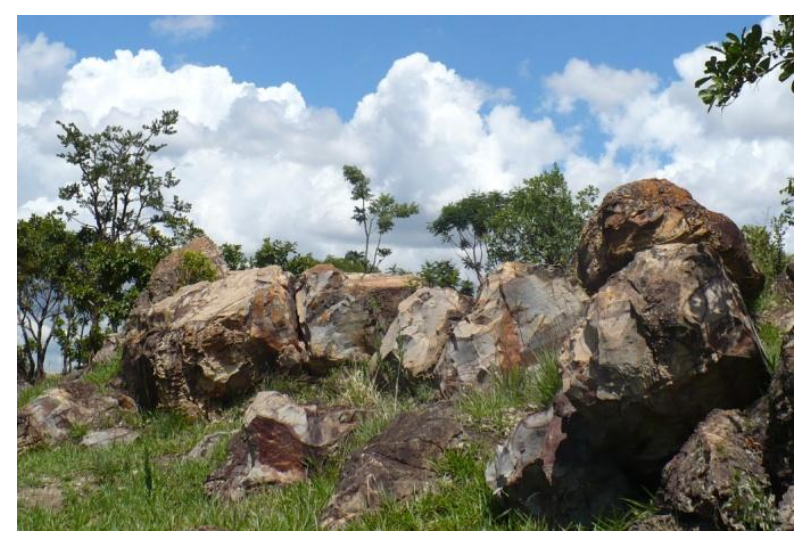

Foto 2: Afloramentos do sítio Bela Vista

No Marajó, o exemplo escolhido tem ruínas coloniais facilmente identificáveis e localizadas em área urbana que já recebe turistas atraídos pela praia e natureza exuberantes. O bem em questão difere dos sítios arqueológicos com inegável potencial turístico na região ${ }^{8}$ e esta foi uma das características que contribuíram para ser nele o estudo piloto da pesquisa. $O$ sítio arqueológico de Joanes localiza-se no distrito de mesmo nome, em uma praça onde atualmente funcionam também equipamentos públicos tais como a Igreja Católica, o centro comunitário, a escola, entre outros. No modelo urbano português trata-se na verdade de um largo, mas o sítio arqueológico (PA-JO-46) é multicomponencial, tem extensão bem maior que o largo e engloba outras estruturas além das ruínas da antiga Igreja de Nossa Senhora do Rosário do século XVII. Na foto 3, é possível ver o campanário da antiga igreja recentemente restaurado pelo IPHAN, durante etapa de campo em julho

${ }^{8}$ O principal exemplo de turismo arqueológico no estado do Para é o Parque Estadual Monte Alegre/PA, localizado no município de mesmo nome a oeste da capital (principal acesso pelo município de Santarém). Fora do Pará, na região Amazônica, existem outros sítios específicos que merecem atenção por sua visibilidade e grande potencial para desenvolvimento turístico: sítios do tipo Geoglifo e o sítio Calçoene no Amapá, composto por megalitos e também conhecido popularmente como Stonehenge brasileiro.

\begin{tabular}{|l|l|l|l|l|l|l|}
\hline (C) Rev. Arqueologia Pública & Campinas, SP & v. 9 & n. 2 & p.87-107 & DEZ 2015 & ISSN 2237-8294 \\
\hline
\end{tabular}




\section{Revista de Arqueologia Pública}

de 2015. Na Imagem 4, percebe-se pessoas visitando as ruínas, nesta imagem o fundo da antiga igreja, registrado em novembro de 2013 durante observação de uma festividade religiosa.

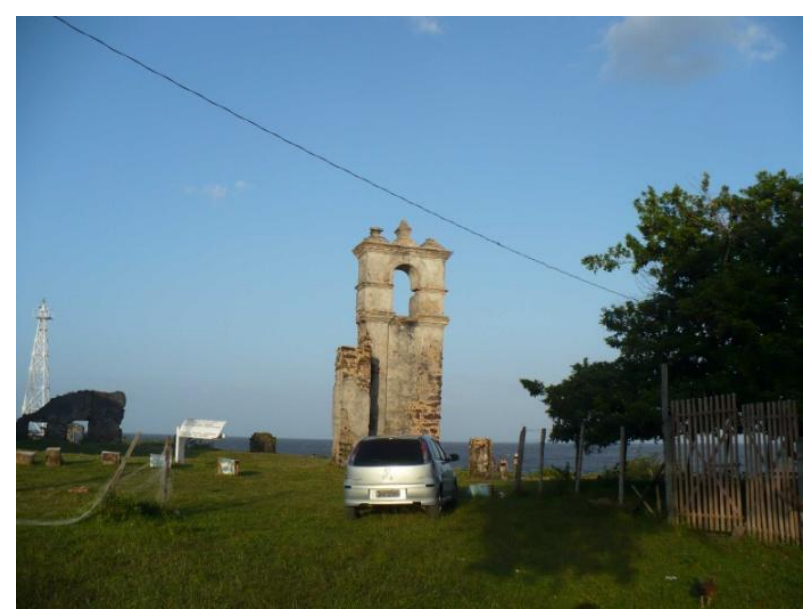

Foto 3: Ruína do campanário em Julho de 2015

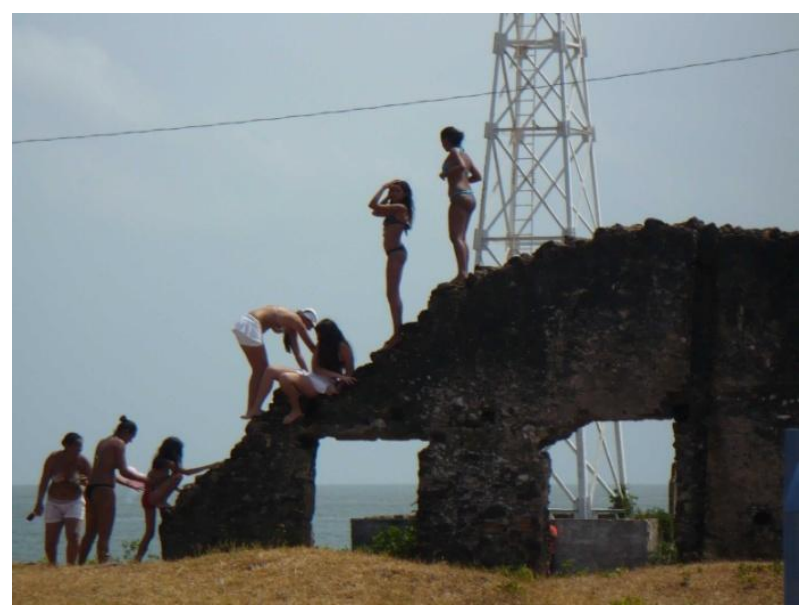

Foto 4: Turistas visitando ruínas em 2013

Nos patrimônios arqueológicos do Parque, no DF, existia uma grande vontade de se aplicar turismo, que não condizia em nada com a realidade da área em questão nem com a própria opinião dos entrevistados quando questionados em relação à sua opinião sobre o parque em si, descrita como uma área vaga, ou de preservação ambiental, mas raramente apontada como um local de lazer que eles próprios utilizariam para visitação. A disparidade entre os discursos e a prática era tremenda, o que não diminui a importância da aspiração do público em relação ao desenvolvimento do turismo no local.

Em Joanes, no Pará, o uso turístico deste patrimônio é notório, mas alguns problemas foram identificados ao longo da pesquisa. O sítio arqueológico Joanes é sempre listado como atração turística local, mas as informações são bastante resumidas e sempre desconexas. Na divulgação

\begin{tabular}{|l|l|l|l|l|l|l|}
\hline (C) Rev. Arqueologia Pública & Campinas, SP & v. 9 & n. 2 & p.87-107 & DEZ 2015 & ISSN 2237-8294 \\
\hline
\end{tabular}




\section{Revista de Arqueologia Pública}

pela internet e na informação coletada durante uma visita guiada (etapa de campo de julho de 2015) a expressão "ruína" se sobrepõe ao fato desta ser apenas um dos componentes do sítio arqueológico.

A necessidade de se aprofundar sobre esse tema, e ao mesmo tempo de avaliar quais têm sido os efeitos causados por tal atividade, considerando não apenas os vestígios e paisagens culturais, mas também os impactos causados nas comunidades anfitriãs é o principal motivador da pesquisa de pós-doutoramento, em andamento. Já a pesquisa de doutorado visava entender qual a motivação de públicos sem vínculo cultural com o patrimônio arqueológico, considerando como hipótese que um destes motivadores poderia ser econômico através de aproveitamento turístico.

A metodologia aplicada em ambas é semelhante, mas o principal conjunto de dados é diferente: em Brasília era através de entrevistas semi-estruturadas, e no Pará a observação participante tem sido o norteador em campo. A metodologia aplicada nas duas pesquisas é o estudo etnográfico rápido (Procedimentos de Investigação Etnográfica Rápida ou Rapid Ethnographic Assessment Procedures - REAP), utilizada em pesquisas em parques na América do Norte com sucesso há mais de uma década (LOW et al., 2005), que combina dados diferentes para uma análise mais ampla e confiável. A seguir as duas pesquisas serão apresentadas brevemente.

\section{No cerrado - sítios pré-coloniais em ambiente rural}

O exemplo em Brasília, como dito anteriormente, foi fruto de uma tese de doutorado, defendida em 2012 nos EUA (GODOY, 2012). Nela buscou-se compreender a principal razão que motiva grupos classificados como não descendentes a criar vínculos com patrimônios arqueológicos, uma situação relativamente corriqueira em ambientes que reúnem diversos grupos étnicos e/ou culturais, como em áreas urbanas. Brasília foi escolhida por ser um estudo de caso que configurou dois extremos: um patrimônio com idade muito antiga, dividindo espaço com populações recentes, no caso sítios líticos em cidades formadas por migrantes no século XX. Especificamente a pesquisa desenvolveu-se na Área de Especial Interesse Ambiental conhecida como ARIE Parque JK (referida ao longo do texto como Parque), com mais de dois mil hectares e localizada à aproximadamente 20 quilômetros de Brasília, entre as cidades-satélite Taguatinga, Ceilândia e Samambaia no Distrito Federal (Mapa 2). 


\section{Revista de Arqueologia Pública}

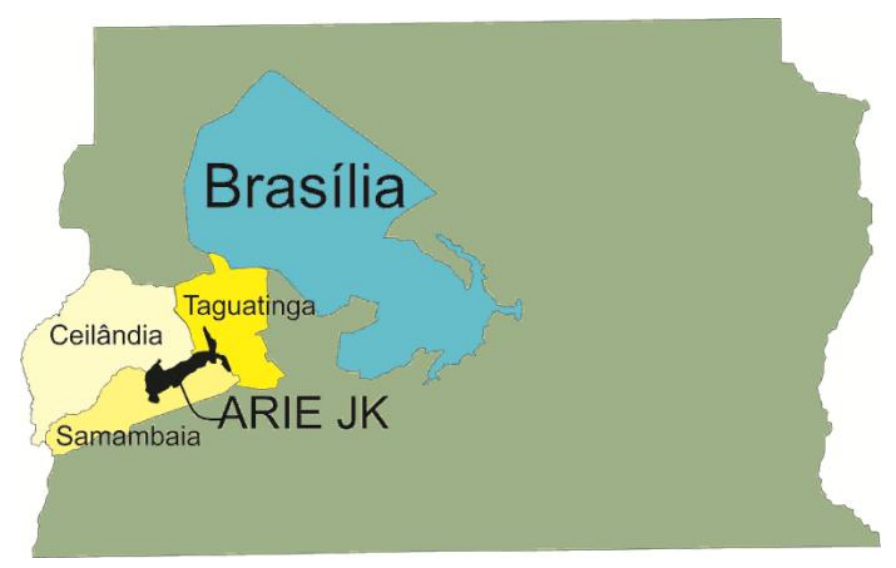

Mapa 2: localização da ARIE JK dentro dos limites do Distrito Federal Godoy, 2015.

Dentro e fora dos limites do Parque pelo menos seis sítios arqueológicos foram registrados entre os anos de 1993 e 2010, sendo que quatro destes sítios foram classificados como oficinas líticas: três pré-históricas que podem chegar a datas tão recuadas como 12 mil anos antes do presente; e uma quarta do período histórico (século XIX). Se por um lado os sítios arqueológicos no Parque apresentam comprovada relevância científica, eles também têm como característica comum a baixíssima visibilidade e questionável apelo estético, o que na teoria diminuiria seu apelo público. Porém, na prática, reivindicações de propriedade e de gestão sobre estes sítios têm ocorrido em diferentes níveis desde os anos 1990, envolvendo ações individuais e institucionais. Tais ações incluem desde manifestações diversas relativas à sua salvaguarda e reivindicações de diversos atores para a criação de um museu local para abrigar as coleções; à significativa atenção da mídia durante as escavações; e até mesmo um episódio de pilhagem de um dos sítios. Estes indícios sugerem o claro o interesse do público local sobre o assunto.

Afinal, por que grupos que não têm vínculo histórico aparente se preocupam com o patrimônio arqueológico? O que realmente motivou moradores do Distrito Federal no engajamento pela preservação destes patrimônios culturais? Em decorrência da falta de vínculos históricos foi sugerido como hipótese principal que a apreciação deste patrimônio pelo público ocorria mais pela influência dos valores extrínsecos, e não exclusivamente em função da significância científica do bem cultural. $\mathrm{O}$ turismo foi indicado como o principal benefício econômico que poderia ser gerado.

Para a análise utilizou-se três tipos de dados: entrevistas semiestruturadas e abertas (considerado o dado norteador); uma amostra selecionada de reportagens de dois jornais locais sobre o Parque e/ou sobre arqueologia; e dados coletados dentro e nas imediações do Parque com observação e registro de vestígios de uso. Nas avaliações sobre turismo buscou-se verificar o uso recreativo que ocorria dentro do Parque, que além dos sítios arqueológicos abriga o fundo de vale do Córrego Taguatinga e cinco parques urbanos.

As análises demonstraram que em relação ao potencial turístico, a prática e o discurso caminham em direções opostas. Os sítios e sua cultural material têm baixíssima visibilidade; não que fosse impossível a musealização deste patrimônio, mas seria um processo complexo e talvez não 
trouxesse o retorno esperado em médio e longo prazos. No entanto, a opinião dos entrevistados vislumbra uso turístico em função da significância científica do patrimônio, muitas vezes ignorando por completo sua cultura material. Em 2008, quando a coleta de dados foi realizada, houve um apelo por parte dos entrevistados para a criação de um museu local, o que continua sendo uma demanda até os dias de hoje. As análises demonstraram que o benefício econômico representado por um possível aproveitamento turístico, em contrapartida, é apenas retórico e não influenciou a opinião pública.

O mais interessante nos dados contrastados foi as respostas de entrevistados ligados à atividade turística e daqueles ligados à atividade arqueológica em comparação aos demais. Nos primeiros grupos, os entrevistados respondiam com cautela, seja pela falta de visibilidade (profissionais do turismo) seja pela preocupação com a preservação do patrimônio (arqueólogos), sendo que um de cada grupo se mostrou contra o aproveitamento turístico dos sítios líticos. $O$ entrevistado vinculado à agência de turismo local relata que existe projeto para desenvolver turismo rural na região dos sítios, visando incluir os produtores locais neste mercado. Seria uma atividade que até poderia incluir o turismo arqueológico, mas que demandaria muito financiamento para facilitar seu acesso, e muita iniciativa do poder público para garantir sua segurança.

Já no grupo classificado como "potencial usuário do Parque" (moradores do entorno ou do Distrito Federal) a opção de uso turístico sempre era recebida com otimismo mesmo que nenhum deles tenha reconhecido o Parque como uma área de lazer. Para a maioria dos entrevistados a arqueologia reforça seu caráter ambiental e incrementa seu status legal; o efetivo uso turístico poderia diminuir os usos ilegais dele, tais como invasões e degradação de toda sorte. Para outros traria visibilidade ao local, aumentaria a importância dali. Para quem reside vizinho a um Patrimônio Mundial da UNESCO ${ }^{9}$, a expectativa destes moradores sobre um possível desenvolvimento turístico, visando usufruir de um o mercado desenvolvido para o Plano Piloto talvez ignore o uso pejorativo que a atividade pode causar, mesmo como uma atração secundária. A visibilidade que a atividade daria ao patrimônio arqueológico "invisível" seria importante para ampliar ações ambientais, para divulgar espaços, para notabilizar ocupações urbanas ainda recentes e sedentas por uma identidade cultural e territorial. Quando confrontados, os dados revelaram que o turismo arqueológico geraria muito mais do que benefício econômico para este estudo de caso, ele tem o poder de agregar capital simbólico ao Parque.

\section{Na Amazônia - sítio colonial em ambiente urbano}

No segundo exemplo, a pesquisa de pós-doutorado (GODOY, 2014) propõe uma reflexão sobre o impacto do turismo arqueológico, considerando sítios que já estão em uso para visitação. A

\footnotetext{
${ }^{9}$ Brasília foi registrada como Patrimônio Mundial em 1987, sendo o primeiro bem cultural do século XX a conseguir este título (UNESCO, 2015).
} 


\section{Revista de Arqueologia Pública}

principal hipótese sugere que planejamento e envolvimento comunitário são necessariamente benéficos em sítios turísticos culturais. São conjecturas ainda pouco testadas, que na prática podem gerar resultados muito diferentes do esperado. E a escolha de um sítio amazônico para tal avaliação não é por acaso.

A arqueologia amazônica fascina leigos e arqueólogos, e tem apresentado ao longo de décadas de pesquisas sítios e coleções únicos, com altíssima relevância científica e inegável potencial turístico. Os sítios da Amazônia brasileira como atrações turísticas por si só chamam atenção pela expectativa de novidade criada pelo público, e pelo aspecto de aventura e descoberta que despertam no turista. E não por coincidência na região amazônica esta temática ganhou um significativo fôlego nos últimos anos, onde é possível encontrar pesquisadores tanto da área do turismo quanto da arqueologia interagindo em projetos de pesquisa, workshops e publicações conjuntas.

No estado do Pará existe pelo menos um grupo de pesquisa com essa configuração, em andamento desde 2006, liderado por Silvio José de Lima Figueiredo, um pesquisador da área do turismo vinculado à UFPA, e pela arqueóloga do Museu Paraense Goeldi, Edithe da Silva Pereira. Dentre outros resultados alcançados por essa colaboração dois merecem destaque: a realização do Workshop Internacional "Turismo e Gestão do Patrimônio Arqueológico", sediado em Belém/PA durante o mês de abril de 2009, produto de uma parceria entre o IPHAN e o Museu Paraense Goeldi; e uma importante publicação lançada em 2012 que reúne os frutos deste evento (FIGUEIREDO, S. J. D. L. et al., 2012).

Outra iniciativa recente no Brasil que reafirma a demanda por projetos exclusivamente voltados para uma integração entre a arqueologia e o público é o edital da Sociedade de Arqueologia Brasileira lançado em 2011, intitulado "Programa de Apoio à Difusão do Conhecimento Arqueológico". Dentre os projetos vencedores pelo menos dois se destacam como propostas de aproveitamento turístico na Amazônia, visto que incluem visitações e participação comunitária como elementos essenciais para preservação de patrimônios arqueológicos: "Arte Rupestre de Monte Alegre" e "Musealização do Geoglifo Tequinho: arqueologia comunitária no Acre".

Afinal, nos locais que recebem visitantes sem nenhum tipo de planejamento os efeitos negativos são maiores em relação à comunidade local, em relação à preservação dos bens materiais, ou em ambos? Existem exemplos bem sucedidos de inclusão da comunidade na Amazônia? Como o patrimônio arqueológico e as comunidades se beneficiariam com tal integração? O envolvimento popular acontece com mais frequência em sítios que tiveram planejamento turístico ou em caso onde a presença de visitantes é espontânea? Quais são os impactos físicos do turismo nos bens materiais? O patrimônio foi adaptado para visitação? Sua autenticidade foi comprometida? A metodologia consiste em pesquisa etnográfica rápida, como exposto anteriormente, amparada em especial pela observação participante a fim de avaliar como o sitio tem sido divulgado e utilizado turisticamente. Também são coletados os seguintes dados para posterior contraste analítico: levantamento bibliográfico; pesquisa de oferta turística referente à coleta e avaliação de dados sobre 


\section{Revista de Arqueologia Pública}

divulgação do sítio que estão disponibilizados para o público em geral através de mídias impressas e digitais; e entrevistas semiestruturadas com arqueólogos coordenadores de pesquisa.

O sítio de Joanes, no Arquipélago do Marajó, foi selecionado como o estudo piloto desta pesquisa por motivos diversos. Trata-se de um sítio ímpar dentre os mais divulgados para o grande público na Amazônia como ponto turístico de fácil acesso a partir de Belém para visitantes da porção oriental do arquipélago do Marajó (Mapa 3). É um sitio multicomponencial (indígena e histórico) onde ainda existem ruínas de uma missão religiosa do século XVII (SCHAAN \& MARQUES, 2011), localizado em um espaço público urbano de Joanes. A quantidade e qualidade de dados já publicados sobre ele em pesquisas anteriores e em andamento também foi um grande motivador para sua escolha.

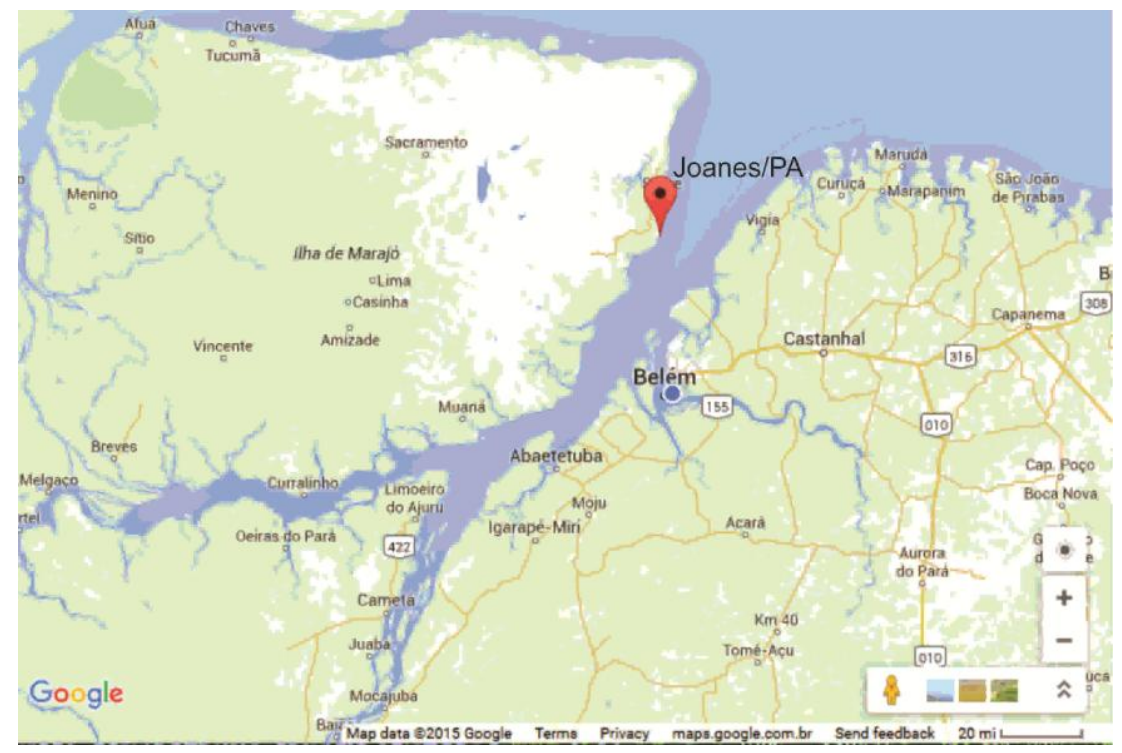

Mapa 3: Localização de Joanes. Google Maps adaptado por Godoy, 2015.

O método da observação participante possibilitou conhecer o estudo de caso como turista, e perceber o fenômeno do turismo em Joanes de uma maneira mais imparcial e abrangente. Em campo, buscou-se avaliar a experiência turística em períodos de maior visitação, durante festividades e mais recentemente em excursão com guia turístico particular. Foram realizadas cinco etapas de campo entre setembro de 2013 e janeiro de 2014, sempre em fins de semana e incluindo dois feriados (15 de novembro e $1^{\circ}$ de janeiro). Em 2015 foi realizada a derradeira visita a campo em julho por ser este o mês da alta estação turística do verão Amazônico. A pesquisa, em andamento, prossegue coletando dados em outros sítios arqueológicos amazônicos e pretende contrastar os dados com os já coletados em Joanes ${ }^{10}$.

${ }^{10}$ Pelo menos mais dois estudos de caso deverão ser analisados até o fim do projeto em 2019, preferencialmente os de melhor acesso e maior demanda turística, a depender da liberação de verbas de taxa de bancada para este fim. 
O que se pode perceber neste estudo de caso é que existem diferentes tipos de turismo em Joanes, e consequentemente motivações atraindo diferentes tipos de visitantes. Tanto Joanes como em toda a porção oriental do Marajó (que inclui os municípios de Salvaterra e Soure) são mais conhecidas pelo turista doméstico por suas praias, o que é classificado como o turismo "sol e mar". Em feriados e na alta temporada, a concentração de visitantes se encontra nas praias, e muitos nem chegam a tomar conhecimento da existência das ruínas de Joanes. Percebeu-se que muitos destes visitantes, quando se interessam em visitar as ruínas, o faz por curiosidade e em momentos em que a praia já não é mais uma opção. Existe também um grupo bastante diferenciado de turistas que procura Joanes por seus atrativos ecológicos, poderíamos chamá-los de "ecoturistas", viajam em grupos ou sozinhos e vêm de outros estados e de outros países. São pessoas que não se limitam aos períodos de alta temporada, e que costumam ter objetivos bem específicos e passeios préarranjados.

Em Joanes, no entanto, o fato mais relevante durante as observações é a forte presença paisagística das ruínas da antiga igreja e do poço associado a esta ocupação colonial em meio ao único espaço público da comunidade. A observação participante na área do sítio arqueológico reforçou o baixo número de visitantes, tendo em todas as ocasiões registrado visitas isoladas e rápidas, nas quais as pessoas circulam pelo entorno das ruínas da igreja e tiram fotos. Não há outros atrativos que justifiquem a presença de turistas no local, e mesmo à noite o uso se limita aos equipamentos urbanos da praça. O sítio arqueológico não possui informações adequadas para turistas. Não existe iluminação nas ruínas, o que diminui a frequência de visitantes, pois eles preferem outras atividades durante o dia. Nas etapas de campo, notou-se uma falta de planejamento turístico generalizado não apenas em relação ao turismo arqueológico, vide a dificuldade de informações, de acesso, de hospedagem e a ausência de outras atividades que fariam os visitantes permanecerem por mais tempo no distrito de Joanes. Em relação ao patrimônio arqueológico, no caso representado especialmente pelas ruínas da antiga igreja, o registro de turistas apesar de baixo em número e em tempo de visitação também identificou uma forma de vandalismo indireto ao presenciar pessoas escalando as ruínas (Foto 4). A falta de controle e a falta de informação prejudicam a preservação dos bens materiais, e neste caso o impacto foi claramente identificado.

Os dados secundários coletados sugerem receio dos moradores antigos em relação aos que vieram depois, impulsionados justamente pelo desenvolvimento turístico, como donos de pequenos comércios e donos de pousadas. Enquanto pequenos comerciantes e proprietários de pousadas se mostravam a favor do turismo, visto que eles certamente se beneficiariam desta iniciativa, outros eram indiferentes ou mesmo contra o uso turístico do sítio arqueológico (SCHAAN \& MARQUES, 2011). Tal constatação também foi encontrada na fala dos arqueólogos entrevistados, em momentos e em formatos diferentes, bem ou mal denotando a mesma resistência dos indivíduos que se identificam como tradicionais ou filhos de Joanes versus os que vieram depois, com outros objetivos e com mais ferramentas para se inserir no mercado gerado pelos turistas. Ou seja, Joanes apresenta características patentes do turismo arqueológico: problemas de preservação do bem

\begin{tabular}{|l|l|l|l|l|l|l|}
\hline (C) Rev. Arqueologia Pública & Campinas, SP & v. 9 & n. 2 & p.87-107 & DEZ 2015 & ISSN 2237-8294
\end{tabular}


cultural e conflitos sociais em virtude do incremento econômico e da presença de pessoas estranhas à comunidade tradicional.

Em contrapartida, duas instituições locais criadas em função (ou por influência) da atividade turística têm o poder de reverter este quadro. A Cooperativa de Desenvolvimento Sustentável de Joanes (COODSJ), voltada para fomentar o ecoturismo e a economia local, surge como uma iniciativa interessante. O blog deles mostra as ruínas do sítio de Joanes como uma opção turística, mas pouco se sabe sobre esta iniciativa além da sua divulgação online e em folders colados em restaurantes na Praia de Joanes. Já a participação cada vez maior da Associação Educativa Rural e Artesanal da Vila de Joanes (AERAJ) na economia do turismo local levanta a hipótese de que a comunidade local tem sim sido beneficiada mesmo que timidamente pelo turismo, mesmo que tal benefício ainda não seja efetivamente o econômico, como é discutido a seguir.

\section{Considerações finais - situações diferentes, resultados semelhantes.}

É fato que turismo bem planejado tem o poder real de tornar o passado mais acessível para diversas pessoas, desde aquelas que se identificam com o patrimônio, porque efetivamente possui vínculos culturais, até o próprio visitante que como expectador também se sente um pouco dono e desenvolve um tipo de vínculo, mesmo que efemeramente. O maior desafio é sem dúvidas conseguir incluir demandas e anseios de comunidades locais afetadas em propostas de aproveitamento turístico antes mesmo de sua implantação. Mas o turismo, por definição, é uma atividade de difícil controle depois de sua implantação.

Os exemplos apresentados não possuem semelhanças no uso turístico, no ambiente em que se encontram, nem sequer no tipo de sítio arqueológico, como já foi discutido anteriormente. No entanto, propõe-se neste artigo, que em ambos a semelhança está na forma com que o uso turístico beneficia a comunidade local (ou no caso de Brasília tem o poder de beneficiar já que a prática não é vigente). Trata-se de um acrescimento coletivo, e não econômico, que aqui é elencado como capital simbólico. Estudos antropológicos mais recentes têm compreendido o turismo como uma nova alternativa econômica, e vislumbrado que tal atividade também pode gerar benefícios culturais para as comunidades locais, analisando como visitantes e o turismo podem se tornar parte integral da cultura.

$\mathrm{Na}$ antropologia brasileira um exemplo interessante foi apresentado por Grünewald (2009: 104) a respeito das respostas de populações indígenas, que quando consultados pela EMBRATUR e em virtude do "turismo predatório nas adjacências de suas terras, preferiram se manter afastados de fluxos turísticos, alegando não precisar desse dinheiro para viver". Este autor também afirma que as populações indígenas que vivem na região norte do Brasil costumam demonstrar desinteresse não apenas pelo contato negativo com turismo, mas também pela falta de apoio da FUNAI e pela dificuldade de acesso às aldeias. Ao mesmo tempo, o turismo cultural também tem sido utilizado como ferramenta de resgate e valorização cultural de grupos indígenas que foram mais afetados pela 


\section{Revista de Arqueologia Pública}

colonização no litoral do país, como no caso dos Pataxós que através de apresentações inicialmente instrumentais promovidas para turistas começam a "reinventar suas tradições". É um exemplo de como o turismo influencia e recria manifestações e tradições culturais de forma positiva, como na abordagem deste artigo que o compreende como favorável para ambos os estudos de caso apresentados.

Em Brasília, a região metropolitana onde estão os sítios estudados é a mais populosa de todo o Distrito Federal, mas popularmente é mais reconhecida como violenta e periférica. No entanto, duas das três cidades-satélite que englobam o Parque têm uma identidade histórica e cultural estabelecida. Taguatinga foi inaugurada ainda antes de Brasília e sua história se confunde com a do Plano Piloto; Ceilândia é tida como uma das cidades mais nordestinas fora do Nordeste em virtude da enorme comunidade migrante de lá e cultiva sua identidade cultural ${ }^{11}$. Samambaia busca por uma identidade que ainda está sendo construída vide a sua criação tão recente ainda no final dos anos de 1980. E foi em Samambaia, e não em Ceilândia, onde os sítios estão localizados, que os maiores esforços surgiram para a criação de um museu arqueológico e para a preservação do sítio Taguatinga ao tentar inseri-lo dentro dos limites do Parque Três Meninas, o único de Samambaia e um dos cinco localizados dentro do grande Parque. A presença de um patrimônio arqueológico tão antigo e tão significante nas Américas muda por completo a referência desta localidade no Brasil e no mundo. E a presença de turistas, a divulgação do sítio como relevante para visitação serve muito mais para este propósito que para o benefício econômico que poderia ser gerado pela atividade.

No caso de Joanes, as observações evidenciaram que o sítio arqueológico é de fato uma atração secundária na vila, pois os turistas almejam, em princípio, aproveitar a praia, e/ou outros passeios ecológicos tais como trilhas ecológicas guiadas ou passeios de barco. Porém, de acordo com pesquisa em andamento de Márcia Bezerra (BEZERRA, 2014), as ruínas têm servido como uma forte identidade visual que diferencia esta comunidade das demais, que identifica Joanes como única, como diferente. A associação das artesãs de lá tem aplicado a imagem das ruínas em diversos produtos, o que gera sim benefício econômico, mas fomenta mais ainda o fortalecimento da identidade cultural dos joanenses, tão ofuscados pela sede municipal em termos de melhorias sociais.

Nos dois casos, por mais distintos que possam parecer, a semelhança encontra-se nos benefícios sociais e políticos que a presença do turismo pode provocar. O beneficio econômico acaba sendo mais maléfico visto que o lucro raramente vai para seus moradores, como constatado no caso de Joanes. Contudo, muitas vezes, a valorização deste mesmo patrimônio começa pela presença de "estrangeiros" interessados em apreciar um bem cultural que a comunidade às vezes desconhece (como no caso de Brasília), ou que às vezes não reconhece, porque ele já faz parte da sua rotina (como no caso de Joanes). O esperado conflito advindo da integração entre preservação

${ }^{11}$ Que inclui a única obra de Oscar Niemeyer fora do Plano Piloto no Distrito Federal, a Casa do Cantador, um centro de tradições nordestinas inaugurado em 1986.

\begin{tabular}{|l|l|l|l|l|l|l|}
\hline (C) Rev. Arqueologia Pública & Campinas, SP & v. 9 & n. 2 & p.87-107 & DEZ 2015 & ISSN 2237-8294
\end{tabular}




\section{Revista de Arqueologia Pública}

cultural e turismo acaba sendo o ponto de partida para ações de preservação e de uso que mudam a conjuntura do lugar, dão visibilidade, aumentam a autoestima local, reinventam ou criam uma identidade cultural.

Ambas as pesquisas apresentadas neste artigo visaram compreender e valorizar percepções culturais diversas acerca do patrimônio arqueológico local como uma forma de identificar significados e motivações especificamente atrelados ao uso turístico deste bem cultural. Entende-se que todos os atores envolvidos no contexto de uso do bem arqueológico, seja como expectador seja como "dono", desenvolvem suas próprias conclusões e estabelecem seus próprios vínculos com patrimônio. Entender tais meios de associação é um ganho para a prática arqueológica (KUHN, 2002). Defendo que, apesar dos notórios impactos que a atividade turística tem causado em patrimônios culturais mundo afora, o turismo é um fenômeno contemporâneo que deve ser compreendido em sua totalidade.

Reafirmo que o turismo pode ser uma excelente estratégia para a Arqueologia Pública, pois ele tem o poder de tornar o passado acessível e atrativo para pessoas de diversas faixas etárias, étnicas e sociais. Se aplicado de forma inteligente e minimamente controlada, buscando integrar benefícios para moradores locais com divulgação e proteção do bem arqueológico, é uma atividade que ocasionará ganhos coletivos e econômicos. E como foi apontado ao longo deste artigo, o turismo arqueológico ainda tem o poder de instigar as pessoas a apreciar uma cultura material sem o apelo estético óbvio como no caso de Brasília; ou de adotar patrimônio como seu, resignificando símbolos cotidianos, como no caso de Joanes.

\section{Referências bibliográficas}

AAS, C.; LADKIN, A.; FLETCHER, J. Stakeholder collaboration and heritage management. Annals of Tourism Research, v. 32, n. 1, p. 28-48, 2005.

ALFONSO, L. P. O Patrimônio Arqueológico e sua Vinculação a Circuitos Turísticos não Convencionais no Brasil. História e-história. 4, 2009.

BAWAYA, M. Archaeotourism. In: VITELLI, K. D. e COLWELL-CHANTHAPHONH, C. (Ed.). Archaeological Ethics. Walnut Creek: AltaMira Press, 2006. p.158-164.

BEZERRA, M. Por uma Bricolage do Passado: Patrimônio Arqueológico, Artesanato e Comunidades Locais na Vila de Joanes, Ilha do Marajó, Amazônia. In: MONTENEGRO, M. e BUENOS, L. M. (Ed.). Multivocalidad y Activaciones Patrimoniales en Arqueología: Perspectivas desde Sudamerica. Buenos Aires: Universidad de Buenos Aires, 2014. p.no prelo.

BONIFACE, P. Tourism and Cultures: Consensus in the making? In: BONIFACE, P. e ROBINSON, M. (Ed.). Tourism and Cultural Conflicts. London: Biddles, 1999. p.287-306.

BONIFACE, P.; FOWLER, P. J. Heritage and tourism in "the global village". New York: Routledge, 1993.

BOURDIEAU, P. O Poder Simbólico. Rio de Janeiro: Bertran, 2000. 


\section{Revista de Arqueologia Pública}

CALDWELL, L. Heritage tourism: a tool for economic development. In: WELLS, P. A. (Ed.). Keys to the Marketplace: Problems and Issues in Cultural and Heritage Tourism. Middlesex: Hisarlik, 1996. p.125-131.

CERQUEIRA, M.; PEREIRA, E. Arqueoturismo no estado do Amazonas - da teoria à prática: o caso da Gruta do Batismo Cadernos do LEPAARQ, v. XI n. 22, p. 168-186, 2014.

COGSWELL, R. Grassroots issues in cultural tourism. In: WELLS, P. A. (Ed.). Keys to the Marketplace: Problems and Issues in Cultural and Heritage Tourism. Middlesex: Hisarlik, 1996. p.1-17.

DARVILL, T. Value systems in archaeology. In: COOPER, M. A.;FIRTH, A., et al (Ed.). Managing archaeology. London: Routledge, 1995. p.40-50.

EASTERLING, D. Residents and Tourism: what is really at stake? Journal of Travel \& Tourism Marketing v. 18, n. 4, p. 49-64, 2005.

FIGUEIREDO, A. M. L. A Função Turística do Patrimônio: questionamentos sobre a idéia de sustentabilidade do turismo cultural. Caderno Virtual de Turismo, Universidade Federal do Rio de Janeiro, v. 5, n. 4, p. 43-49, 2005.

FIGUEIREDO, S. J. D. L.; PEREIRA, E. S.; BEZERRA, M. Turismo e Gestão do Patrimônio Arqueológico. Belém: IPHAN, 2012. 196.

FIGUEIREDO, S. L.; PEREIRA, E.; BEZERRA, M. Turismo e Gestão do Patrimônio Arqueológico. Belém: Instituito do Patrimônio Histórico e Artístico Nacional - IPHAN, 2012.

FUNARI, P. P. A.; PINSKY, J., Eds. Turismo e Patrimônio Cultural. São Paulo: Editora Contexto, 1st ed. 2001.

GODOY, R. D. Public Archaeology and Heritage Value(S): learning from urban environments in central Brazil. 2012. 303 (PH.D.). Department of Anthropology, University of Florida, Gainesville.

O Público e a Arqueologia: uma reflexão sobre os efeitos do turismo em sítios amazônicos. Plano de Estágio Pós-Doutoral. Belém: Universidade Federal do Pará. Programa de Pós-Graduação em Antropologia - PPGA. Coordenação de Aperfeiçoamento Pessoal de Nível Superior - CAPES 2014.

GOVERNO. Amazônia. 2015a. Acesso em: 20 de Dezembro. Disponível em: http://www.mma.gov.br/biomas/amaz\%C3\%B4nia

Cerrado. 2015b.

$\overline{\mathrm{http}: / / \mathrm{w} w w \cdot m m a . g o v \cdot b r / b i o m a s / c e r r a d o}$

Acesso em: 20 de Dezembro. Disponível em:

GRÜNEWALD, R. D. A. Indigenismo, turismo e mobilização étnica. In: GRABURN, N.;BARRETTO, M., et al (Ed.). Turismo e antropologia: Novas abordagens. São Paulo: Papirus Editora, 2009. p.97-118.

GUIMARÃES, A. M. Aproveitamento Turístico do Patrimônio Arqueológico no Municipio de Iranduba, Amazonas. 2012. (Doutorado). MAE/USP, Universidade de São Paulo, São Paulo.

GUTIERREZ, E. et al. Linking communities, tourism \& conservation: a tourism assessment process. Washington: Conservation International, The George Washington University 2005.

HECKENBERGER, M. J. Entering the Agora: archaeology, conservation, and indigenous peoples in the Amazon. In: COLWELL-CHANTHAPHONH, C. e FERGUSON, T. J. (Ed.). Collaboration in

\begin{tabular}{|l|l|l|l|l|l|l|} 
(C) Rev. Arqueologia Pública & Campinas, SP & v. 9 & n. 2 & p.87-107 & DEZ 2015 & ISSN 2237-8294
\end{tabular}


archaeological practice: engaging descendant communities. Walnut Creek: AltaMira 2008. p.243-272.

JAMAL, T. B.; GETZ, D. Collaboration theory and community tourism planning. Annals of Tourism Research, v. 22, n. 1, p. 186-204, 1995.

LIMA, H. P.; MORAES, B. M.; PARENTE, M. T. V. "Tráfico" de material arqueológico, turismo, e comunidades ribeirinhas: experiências de uma arqueologia participativa em Parintins, Amazonas. Revista de Arqueologia Pública, n. 8, p. 61-77, 2013.

LOVATA, T. R. Archaeology as Built for the Tourists: The Anasazi Cliff Dwellings of Manitou Springs, Colorado. International Journal of Historical Archaeology v. 15, n. 2, p. 194-205, 2011.

LOW, S. M.; TAPLIN, D.; SCHELD, S. Rethinking urban parks: public space and cultural diversity. Austin: University of Texas Press, 2005. 226.

LUCAS, M. T. Applied archaeology and the construction of place at Mount Calvert, Prince George's County, Maryland. In: SHACKEL, P. A. e CHAMBERS, E. J. (Ed.). Places in Mind: Public Archaeology as Applied Anthropology. London, New York Routledge, 2004. p.119-134.

MACHADO, N. T. G.; LOPES, S. N.; GHENO, D. A. Arqueologia Histórica e a Problemática do Patrimônio: discussões acerca da preservação, turismo e educação patrimonial no Vale do Taquari. História, São Paulo, v. 28, n. 1, p. 575-587, 2009.

MANZATO, F. Turismo arqueológico no estado de São Paulo. História e-história. 4: 1-11 p. 2005.

MCDAVID, C. From 'traditional' archaeology to public archaeology to community action. In: SHACKEL, P. A. e CHAMBERS, E. J. (Ed.). Places in Mind: Public Archaeology as Applied Anthropology. London, New York: Routledge, 2004. p.35-56.

MCGIMSEY, C. R. Public Archaeology. New York: Seminar Press, Inc, 1972.

MCKERCHER, B.; CROSS, H. D. Cultural Tourism: the partnership between Tourism and Cultural Heritage Management Binghamton: Haworth 2002.

MELLO, P. J. C.; DANTAS, J. D. M. M. Situação atual da atividade turística em São Cristóvão (Sergipe, Brasil). Revista de Arqueologia Pública, LAP/NEPAM/UNICAMP, n. 9, p. 95-110, 2014.

MERRIMAN, N. Introduction: diversity and dissonance in public archaeology. In: MERRIMAN, N. (Ed.). Public Archaeology. London: Routledge, 2004. p.1-17.

MIRANDA, R. D. S. Turismo Arqueológico: a potencialidade turística dos naufrágios, tesouros de terra e mar existentes no município de Mostardas-RS. 2010. (Bachelor). Curso de Turismo, Universidade Luterana do Brasil, Torres.

MOREIRA, G. L. Análise do Potencial Arqueoturístico na Comunidade de Moju-PA. V Encontro Nacional da Anppas. Florianópolis 2010.

NUŇES, T. Touristic Studies in Anthropological Perspective. In: SMITH, V. L. (Ed.). Hosts and Guests: the Anthropology of Tourism. Philadelphia: University of Pensylvania Press, 1989. p.265279.

ONUMA, R. M. S. Turismo Arqueológico na cidade de São Paulo, em particular sobre o Pátio do Colégio. 2007. (Bachelor). Curso de Turismo, Universidade Estadual Paulista "Júlio de Mesquita Filho" São Paulo. 


\section{Revista de Arqueologia Pública}

PEREIRA, E.; FIGUEIREDO, S. L. Arqueologia e Turismo na Amazônia: Problemas e Perspectivas. Cadernos do LEPAARQ, v. 2, n. 3, p. 21-35, 2005.

PINTER, T. L. Heritage Tourism and Archaeology: critical issues. The SAA Archaeological Record 5: 9-11 p. 2005.

PORIA, Y.; BUTLER, R.; AIREY, D. The core of heritage tourism. Annals of Tourism Research, v. 30, n. 1, p. 238-254, 2003.

ROBINSON, M. Cultural conflicts in tourism: inevitability and inequality. In: BONIFACE, P. e ROBINSON, M. (Ed.). Tourism and Cultural Conflicts. London: Biddles, 1999. p.1-32.

SCATAMACCHIA, M. C. M. Turismo e Arqueologia. São Paulo: Aleph, 2005.

SCHAAN, D. P.; MARQUES, F. L. Por que não um filho de Joanes? Arqueologia e comunidades locais em Joanes, Ilha de Marajó. Revista de Arqueologia/Sociedade de Arqueologia Brasileira, São Paulo, v. 25, n. 1, p. 106-124, 2011.

SEABRA, G. Apresentação. In: SEABRA, G. (Ed.). Turismo de base local: identidade cultural e desenvolvimento regional. João Pessoa: Editora Universitária/UFPB, 2007. p.11-13.

SHACKEL, P. A. Introduction: Working with Communities - Heritage Development and Applied Archaeology. In: SHACKEL, P. A. e CHAMBERS, E. J. (Ed.). Places in Mind: Public Archaeology as Applied Anthropology. London, New York: Routledge, 2004. p.1-16.

SMITH, M. K. Issues in Cultural Tourism Studies. London: Routledge, 2003.

SWARBROOKE, J. The future of the past: Heritage tourism into the 21 st century. In: SEATON, A. V. (Ed.). Tourism: The State of the Art. New York: John Wiley \& Sons, 1994. p.222-229.

UNESCO. World Heritage List - Brasília. 2015. Acesso em: 20 de Dezembro. Disponível em: http://whc.unesco.org/en/list/445.

VELOSO, T. P. G.; CAVALCANTI, J. E. A. O turismo em sítios arqueológicos: algumas modalidades de apresentação do patrimônio arqueológico. Revista de Arqueologia, n. 20, p. 155-168, 2007. 